\title{
Synthesis of Oil Miscible Novel Silane Functionalised Imidazoline-Based ILs as Lubricant Additives: Characterization and Tribological Evaluations
}

\author{
Priya Pandey ${ }^{1,2}$ (D) Anthony E. Somers ${ }^{1} \cdot$ Samik K. Hait $^{2} \cdot$ S. S. V. Ramakumar ${ }^{2}$
}

Received: 17 September 2021 / Accepted: 21 January 2022 / Published online: 8 February 2022

(c) The Author(s) 2022

\begin{abstract}
The present study investigated the synthesis of novel, oil miscible, multifunctional, silane functionalized imidazolinebased ionic liquids (ILs) with an emphasis towards halogen, sulfur and phosphorous free lubricant additives to replace the conventional additives (ZDDP, MoDTC, etc.), for which there are environmental concerns. These ILs were prepared in different concentrations and proved to be oil miscible for a short time. This stability was improved to over a year using sorbitan trioleate as an emulsifier additive. These additives performed well in reducing friction and wear when investigated on steel-steel contacts at a $5 \mathrm{wt} \%$ concentration, with improvements for the TPEIPS BEHP containing blend of up to 39\% and 53\%, respectively, as compared to the base oil. SEM and EDS analysis shows a phosphorous and oxygen rich tribo-film formation for this combinations. These ILs were further tested to determine their effect on properties such as viscosity, thermal stability, elastomeric and antifoaming compatibility. These new ILs work towards the discovery of environmentally friendly additives for tribological processes.
\end{abstract}

Keywords Ionic liquid $\cdot$ Silane functionalised $\cdot$ Imidazoline $\cdot$ Sorbitan trioleate

\section{Introduction}

Lubricants have been indispensable through history with their motivation progressively shifting from 'mobility' to 'durability' and more recently to 'energy efficiency'. Improvement in machinery can only happen if there is a constant enhancement in lubricant research in terms of energy efficiency, durability, service life and emissions reductions. It is estimated that if the viscosity of automotive oil could be reduced by $25 \%$, fuel savings of $8 \%$ could be made [1], but to achieve lower viscosities more effective lubricant additives are needed to reduce wear. Lubricant additives are mixed with oil in low concentration, with one of the most extensively used anti-wear additives being ZDDP [2]. However, there is constant research to replace such conventional

Priya Pandey

doc.ppandey@gmail.com

1 Institute for Frontier Materials, Deakin University, 221 Burwood Hwy, Burwood, VIC, Australia

2 R\&D Centre, Indian Oil Corporation Ltd., Faridabad 121007 , India lubricant additives with those that are free from halogen, phosphorous, sulfur, and metal content and are environmentally safe [3].

Ionic liquids (ILs) as lubricant additives offer the opportunity to improve the performance due to its properties such as low volatility, flammability, high thermal stability, viscosity, corrosion inhibition, ashless, conductivity, customised molecular structure and tribological efficiency [4-8]. Recently, development of environmentally friendly lubricants including carboxylates and fatty acids have been used as neat or as an additives either in aqueous phase or mineral oil [9-12]. Avilés et al. studied protic ILs such as bis (2-hydroxy ethyl) ammonium palmitate (DPA) for which ultra-low friction was found at high temperature [13]. However, despite showing good tribo-performance these are neither cost-effective nor flexible in different varieties of BO (polar and non-polar), restricting its application to the wider aspects of lubrication.

In our previous work, we have seen that the imidazolium-based IL, 1-butyl-3-methylimiidazolium phosphate showed significant friction reduction [14] and was made oil miscible in both polar and non-polar base oil (BO) through the use of particular surfactants for each BO. 
While the use of surfactants worked for a range of ILs, it was easier to achieve stability for the long-chain ILs based on the trihexyl(tetradecyl)phosphonium-based cation [15, 16]. The imidazolium-based cation with its inherit polarity and aromaticity, which made it more difficult to achieve solubility in the non-polar BO. It is proposed that this can be solved by developing a structure similar to imidazolium but incorporating aliphatic character into the structure $[17$, 18]. Here, novel imidazoline-based ILs were synthesized and investigated as lubricant additives which are aliphatic, lacking one $\pi$ bond, which results in more basicity as compared to imidazolium-based ILs. This aliphatic property may improve miscibility, while an increased basicity may result in an improved ability to deal with acids produced from break-down, contamination and oxidation by-product which may cause corrosion, sludge and varnish formation. If these breakdown products can be minimized performance of the lubricant can be maintained, resulting in longer use before needing to change the oil. Additionally, surfactant chemistry plays an crucial role in the miscibility of both short-chain imidazolium and long-chain phosphonium-based ILs $[15,16]$.

The hydrophobic/hydrophilic nature of ILs is also important in lubrication. Hydrophilic ILs that have been tested as lubricants were prone to water contamination, causing unfavorable chemical reactions and physical changes [19], therefore these hydrophobic ILs have better tribological performance, chemical, thermo-oxidative stability and are also more likely to be oil miscible. Additionally, while the hydrophobicity of the ILs tested here was not chosen specifically for tribological reasons, researchers have found that a hydrophobic surface has a lower free energy, which can reduce adhesion and friction force generated by the contact surface [20].

This work focus on the synthesis of two novel silane functionalised imidazoline-based hydrophobic ILs, triethoxyl-3(-2-imidazolin-1-yl)propylsilane bis 2-ethyl hexyl phosphate viz. TPEIPS BEHP and triethoxyl-3(-2-imidazolin-1-yl)propylsilane 2-ethyl hexanoate TPEIPS EHA (Fig. 1) which are free from sulfur, halogens, and are either very low in phosphorous (TPEIPS BEHP), or have none (TPEIPS EHA), which hamper the longevity and may lead to environmental concern or corrosion. The silane functionalization may not only provide good adhesion to protect the surface [21] but is also known for its antifoaming ability [22]. These cations are also reported to form protective layers on pipes, tank linings and silicone rubbers due to interfacial bonding between the silane and the substrate (glass, metallic, organic) [23]. Imidazoline-based materials have shown anti-corrosion [24], anti-bacterial, anti-fungal [25], thermal stability [26] and film formation ability [27], as well as low toxicity [28]. Here, the shelf life and oil stability in a non-polar BO was also investigated with or without an additional lubricant emulsifier additive; sorbitan trioleate.

\section{Experimental}

\subsection{Chemicals and Materials}

Triethoxyl-3(-2-imidazolin-1-yl)propylsilane (TPEIPS) ( $\geq 97 \%)$, bis(2-ethylhexyl)hydrogen phosphate (HBEHP) (97\%), 2-ethylhexyl hexanoic acid ( $\geq 99 \%)$ and sorbitan trioleate were purchased from Sigma-Aldrich. III group BO
Fig. 1 Structure of ionic liquids synthesized and emulsifier additive used

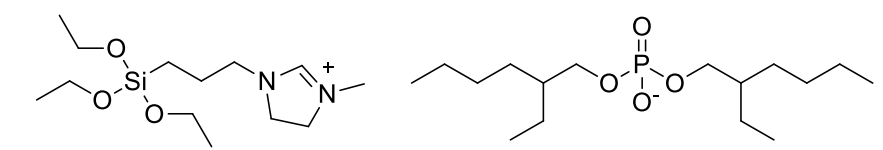

3-methyl-1-(3-(triethoxysilyl)propyl)-4,5-dihydro-1H-imidazol-3-ium bis(2-ethylhexy phosphate (TPEIPS BEHP)
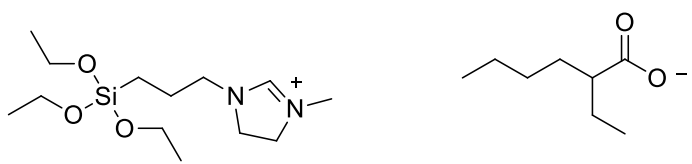

3-methyl-1-(3-(triethoxysilyl)propyl)-4,5-dihydro-1H-imidazol-3-ium 2-ethylhexanoate (TPEIPS EHA)

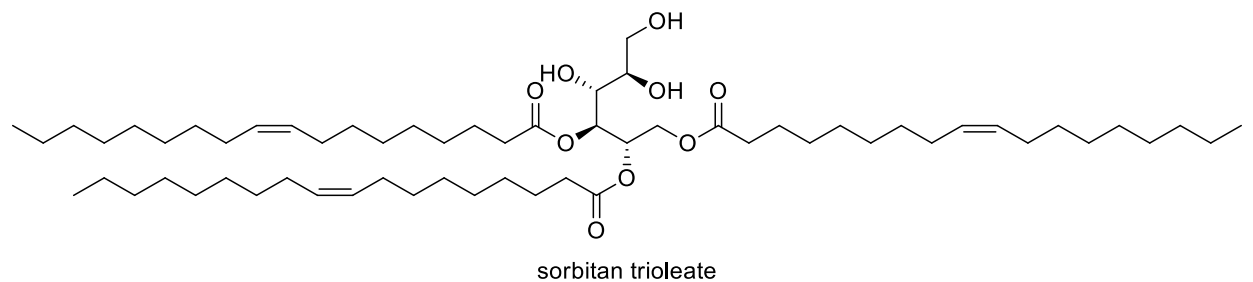


was used which was manufactured in Indian Oil Corporation Ltd, India.

Figure 1 shows the structure of ILs synthesized and the sorbitan trioleate used as an emulsifier additive.

\subsection{Methodology}

The imidazole functionalized materials, triethoxyl-3(-2-imidazolin-1-yl)propylsilane (TPEIPS) were added to bis (2-ethylhexyl) hydrogen phosphate (HDEHP) or 2-ethylhexyl hexanoate (EHA) in equimolar ratio mixed with $20 \mathrm{ml}$ acetonitrile solution in a round bottom flask. The mixtures were refluxed for $24 \mathrm{~h}$ under nitrogen atmosphere. After $24 \mathrm{~h}$, the mixtures were cooled, washed with acetonitrile, chloroform and dried under vacuum at $45^{\circ} \mathrm{C}$.

\subsection{Instrumentation}

\subsubsection{NMR}

The ILs were characterized by ${ }^{1} \mathrm{H}$ and ${ }^{13} \mathrm{C}$ NMR using a Jeol ECA-500 spectrometer operating at $500 \mathrm{MHz}$ and $125 \mathrm{MHz}$, respectively. TMS was selected as a reference $(0.0 \mathrm{ppm})$ and was performed in $\mathrm{CDCl}_{3}$ solvent.

\subsubsection{FTIR}

An IR Prestige-21 Infrared spectrometer (DLATGS detector) from Shimadzu Corp., Japan was used for FTIR analysis. The acquisition parameters were wavelength range: $4000-400 \mathrm{~cm}^{-1}$, resolution: $4 \mathrm{~cm}^{-1}$, scans: 50 . Spectra were processed for base line correction, smoothing and peaks using IR Solution software.

\subsection{Oil Solubility}

The synthesized ILs were formulated in $5 \mathrm{wt} \%$ and $1 \mathrm{wt} \%$ in a group III, non-polar BO, which has a viscosity index greater than 100 and viscosity of $42 \mathrm{cSt}$ at $100{ }^{\circ} \mathrm{C}$. These blends were stirred for $1 \mathrm{~h}$ at $45{ }^{\circ} \mathrm{C}$ and allowed to rest. If the solution appeared completely miscible it was centrifuged at more than 10,000 rpm, allowed to rest and was monitored at room temperature for a month. Oil miscibility and stability was improved using the emulsifier additive sorbitan trioleate, which also imparts multifunctionality.

\subsection{Viscosity Measurement}

Dynamic Viscosity were measured at varying temperature with a TA Rheometer instrument using a $40 \mathrm{~mm}$ parallel plate, Peltier plate steel. There was not sufficient volume of the neat ILs, as the instrument requires $23 \mathrm{ml}$ of the sample, most of which cannot be recovered without contamination and so a significant fraction of the novel synthesized ILs would be lost. As a result, the repeats were performed for the same blends. The IL containing blends were tested and compared with the $\mathrm{BO}$ at variable shear rates (1.21 to 121.34 $1 / \mathrm{s})$ and temperatures $\left(30^{\circ} \mathrm{C}\right.$ to $\left.60^{\circ} \mathrm{C}\right)$.

\subsection{Tribological Testing}

The wear test was carried out using a Falex four ball tester, according to ASTM D-4172-A, where the steel ball was covered with the test lubricant and rotated against three lubricated, stationery steel balls under a specified $15 \mathrm{~kg}(147 \mathrm{~N})$ load, $1200 \mathrm{rpm}$ at $75{ }^{\circ} \mathrm{C}$ for $1 \mathrm{~h}$ and wear scar diameter (WSD) was measured. A lubricant amount of $10 \mathrm{ml}$ was used for each test which was performed three times with the average presented.

Coefficient of friction (COF) test was measured using an optimol SRV oscillating friction tester with $200 \mathrm{~N}$ load at a frequency of $50 \mathrm{~Hz}$ and a $1 \mathrm{~mm}$ stroke length at $100{ }^{\circ} \mathrm{C}$ for $1 \mathrm{~h}$. Here, $5 \mathrm{ml}$ of the sample was required for each test and the average of three readings was taken.

\subsection{Elastomeric Compatibility as Per ISO 6072-1986} (E)

This method is used to test compatibility of elastomeric materials such as Nitrile butadiene rubber (NBR), Viton and FPM (fluoro elastomers) etc. These elastomeric materials are immersed in the test lubricant at $100{ }^{\circ} \mathrm{C}$ for 7 days. The volume (swell/shrinkage) and hardness was measured before and after the test. This test was conducted for one of the ILs synthesized in $1 \mathrm{wt} \%$ in the BO. The optimum result is a very small change in the hardness and volume of the test elastomeric material.

\subsection{Foaming Test as Per ASTM D 892}

This test was performed using a Lawler dual foam bath (model 28), which determines the foaming capacity of a lubricant at $24{ }^{\circ} \mathrm{C}$ and $93.5^{\circ} \mathrm{C}$. The foaming in an oil is a serious issue which may hamper the performance of lubricant. In this process, the test lubricant is maintained at both temperature and air is blown at constant rate of $94 \mathrm{ml} / \mathrm{min}$ for $5 \mathrm{~min}$ and then allowed to rest for $10 \mathrm{~min}$. The volume of foam is measured at the end of $10 \mathrm{~min}$.

\section{Results and Discussion}

\subsection{NMR}

These ILs were not fully miscible in most of the deuterated solvent such as DMSO, $\mathrm{CD}_{3} \mathrm{COCD}_{3} .{ }^{1} \mathrm{H}$ and ${ }^{13} \mathrm{C}$ NMR 
were performed in $\mathrm{CDCl}_{3}$, and were only stable for a limited time before separation. All the composition peaks of imidazoline, silane and the anion viz. carboxylate/phosphate were visible, but due to the absence of complete miscibility in the deuterated solvent the NMR was not presented. The composition of the ILs was further confirmed by IR.

\subsection{IR Technique}

Figure 2 shows the IR spectra of the ILs formed. It shows characteristics peak around $1083 \mathrm{~cm}^{-1}$, corresponding to $\mathrm{Si}-\mathrm{O}-\mathrm{Si}$ stretching, imidazoline shows several peaks with $\sim 1638 \mathrm{~cm}^{-1}$ indicating the presence of $\mathrm{C}=\mathrm{N}$ bond, $1544 \mathrm{~cm}^{-1}$ are the stretching vibration of $\mathrm{C}-\mathrm{N}$ bond, which are the characteristic absorption peaks of the imidazoline ring and $2941 \mathrm{~cm}^{-1}$ shows the stretching vibration of $\mathrm{CH}$ band.

For the 2-ethyl hexanoate anion, a sharp peak at $1705.40 \mathrm{~cm}^{-1}$ indicates the presence of functional carbonyl stretching and the $\mathrm{C}-\mathrm{O}$ stretch bend at $1290 \mathrm{~cm}^{-1}$ while in the case of bis-2-ethyl hexyl phosphate, a peak for phosphate was found at 1203.55 and $969.56 \mathrm{~cm}^{-1}$, which confirms the structure of the formed ILs.

If these ILs were compared with neat cation i.e. triethoxyl-3(-2-imidazolin-1-yl) propylsilane [29], neat BEHP [30] and EHA [31], there was shifting of the peak of the cation and anion precursor suggesting the interactions and formation of salts of IL. However, the purity of formed ILs cannot be quantified based on the limited characterization, if some initial precursor was present it will not be detrimental for the lubricant performance.

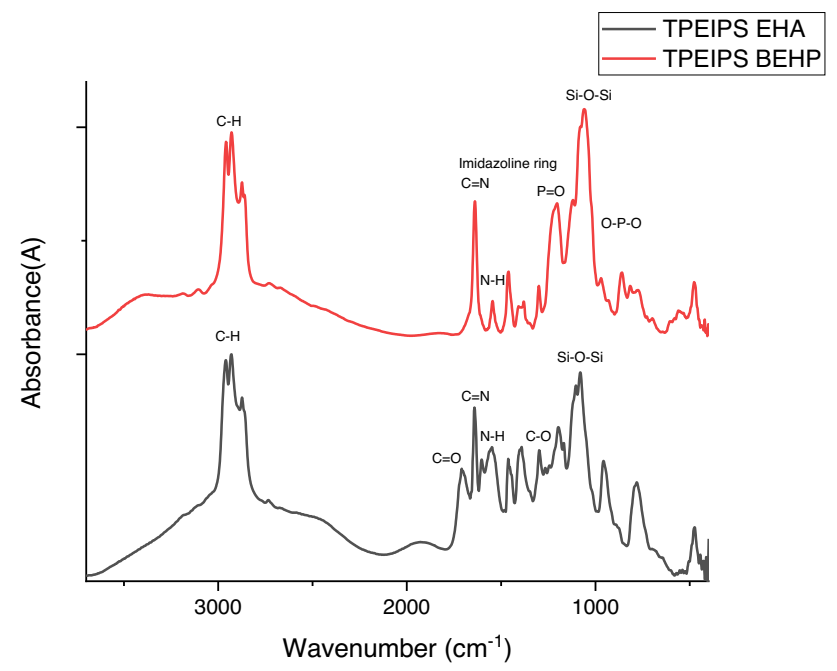

Fig. 2 IR of the ILs synthesized: TPEIPS EHA and TPEIPS BEHP

\subsection{Oil Miscibility Test}

The cation and anion precursor used for the formation of ILs were oil miscible, however when the nature of both these are combined as ILs, they were found to be oil miscible in the BO for a shorter period of time (1-2 days). This means that the interaction between the cation and anion as IL hindered the miscibility in spite of both the compositions individually being miscible in the $\mathrm{BO}$. The influence of the IL additives on the $\mathrm{BO}$ constituents were crucial in a number of aspects, from miscibility to tribo-performance. Also, there was influence of it on viscosity and thermal stability.

The stability of these ILs were improved using the multifunctional emulsifier additive sorbitan trioleate which has improved the oil miscibility to at least 7 months without any sign of turbidity. The ratio used was $1: 2$ by wt\% (IL: sorbitan trioleate).

\subsection{Viscosity}

Dynamic viscosity at variable temperature and increasing shear rate for BO, $1 \mathrm{wt} \%$ of TPEIPS EHA in BO and $1 \mathrm{wt} \%$ of TPEIPS BEHP in BO were examined (Fig. 3). Typically viscosity is governed by interaction forces such as Van der Waals, electrostatic and hydrogen bonding. Depending on the structure of the ILs, the interaction forces which predominates over one another change [32]. Therefore they could play a role in viscosity, which is important in lower pressure contact modes and high velocities, where film thickness and fluid properties determine friction and wear.

The viscosity of the IL containing blends was similar to the $\mathrm{BO}$ which was expected as only $1 \mathrm{wt} \%$ of additive was added. There was a drop in dynamic viscosity up to $33 \%$ for every $10{ }^{\circ} \mathrm{C}$ increase for the case of $\mathrm{BO} / 1 \mathrm{wt} \%$ TPEIPS EHA with sorbitan trioleate formulation. There is slight variation in the behavior the two ILs at different temperature i.e. at $30{ }^{\circ} \mathrm{C}$, the order of dynamic viscosity was BEHP $>$ EHA $>$ BO while as the temperature increases to $60^{\circ} \mathrm{C}$ both the additives shows similar viscosity and the influence of shear rate on the dynamic viscosity of the blend was negligible. These differences in dynamic viscosity of the TPEIPS EHA and TPEIPS BEHP blends could arise from the small variations in the concentration of ILs.

\subsection{Thermal Stability}

According to the thermal decomposition report through TGA, (Fig. 4) operating under inert nitrogen conditions with a constant heating rate, it was observed that the neat IL viz. TPEIPS EHA and TPEIPS BEHP started decomposing at lower temperatures (around $180{ }^{\circ} \mathrm{C}$ and $250{ }^{\circ} \mathrm{C}$ ) than the BO. Also, the thermal stability of the carboxylate anion (EHA) was lower than the phosphate anion (BEHP). This suggests 
Fig. 3 a Viscosity of base oil [BO] (black), 1 wt\% TPEIPS EHA/sorbitan trioleate/base oil [TPEIPS EHA BO] (red) and $1 \mathrm{wt} \%$ TPEIPS BEHP sorbitan trioleate/base oil [TPEIPS BEHP BO] (blue) at variable temperature. b Viscosity of base oil; 1 wt\% TPEIPS EHA/ sorbitan trioleate/base oil; $1 \mathrm{wt} \%$ TPEIPS BEHP/sorbitan trioleate/base oil at $30^{\circ} \mathrm{C}$. c Viscosity of base oil; $1 \mathrm{wt} \%$ TPEIPS EHA/sorbitan trioleate/ base oil; $1 \mathrm{wt} \%$ TPEIPS BEHP/ sorbitan trioleate/base oil at $60{ }^{\circ} \mathrm{C}$ (Color figure online)

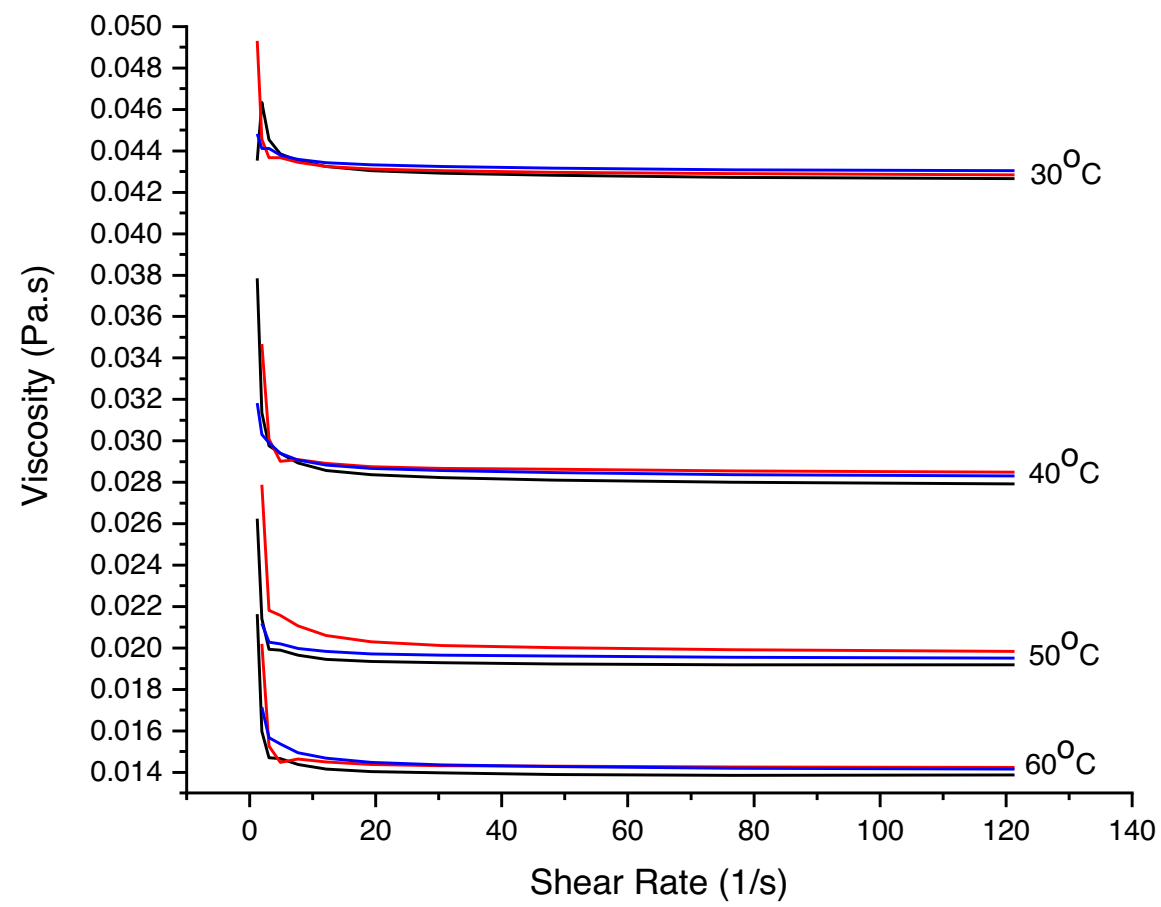

(a)

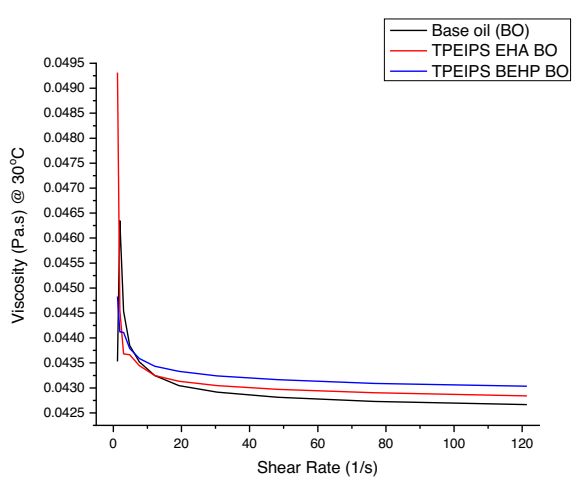

(b)

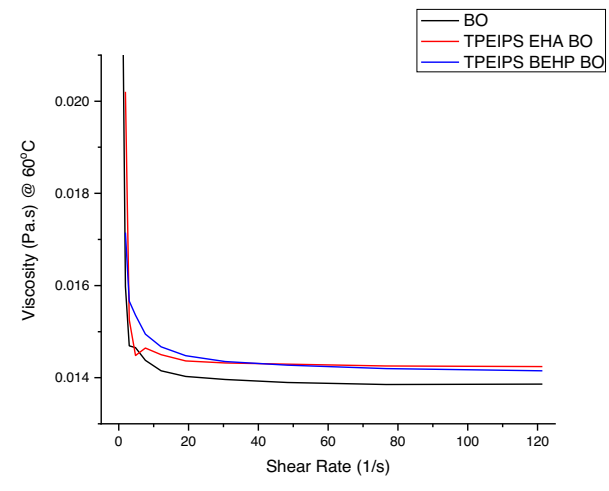

(c) more oxygen in the structure which causes lower $\mathrm{T}_{\text {onset }}$ while the presence of phosphorous may reduce the decomposition rate. The $\mathrm{BO}$ was also tested with the same concentration of the emulsifier additive sorbitan trioleate which was used in the blends and was found that the presence of the surfactant does not affect the thermal stability of the BO. Also when $1 \mathrm{wt} \%$ of the ILs along with the sorbitan trioleate was formulated with the BO, there was comparable or slight improvement in the thermal stability in comparison with the BO ( $\mathrm{T}_{\text {onset }}$ was around $\left.310^{\circ} \mathrm{C}\right)$. The ILs additives at $1 \mathrm{wt} \%$ show a slight increase or comparable thermal stability w.r.t $\mathrm{BO}$ and the weight loss were lower as compared to BO and neat IL. These result shows improvement in thermal stability w.r.t to the neat IL and none of the final combinations was acting in detrimental fashion in reducing the $\mathrm{T}_{\text {onset }}$ w.r.t BO.

\subsection{Tribological Test}

The wear scar diameter was thoroughly studied to understand the role of IL cation and anion, emulsifier, neat IL and BO in this process, with the results shown in Fig. 5. The error bars are the standard error for the instrument, given as $0.05 \mathrm{~mm}$, which is larger than the standard deviation, thus differences of $0.1 \mathrm{~mm}$ in wear diameter are significant. The BO was blended with the emulsifier only in the same concentration as used in the $5 \mathrm{wt} \%$ additive blends and there was a decrease in the wear scar diameter of around $39 \%$. This suggest that the addition of sorbitan trioleate forms a protective film on the steel surface which was not only capable of reducing wear but also improved the oil stability of the ILs. Thus, the sorbitan trioleate 


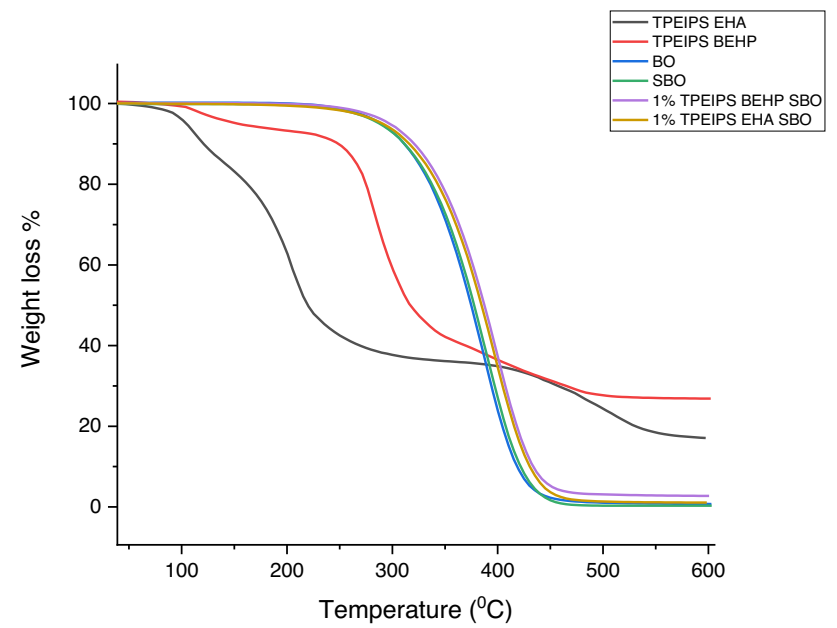

Fig. 4 TGA plot of base oil (BO); sorbitan trioleate/BO (SBO); neat TPEIPS EHA; neat TPEIPS BEHP; 1 wt $\%$ TPEIPS BEHP SBO and $1 \mathrm{wt} \%$ TPEIPS BEHP SBO

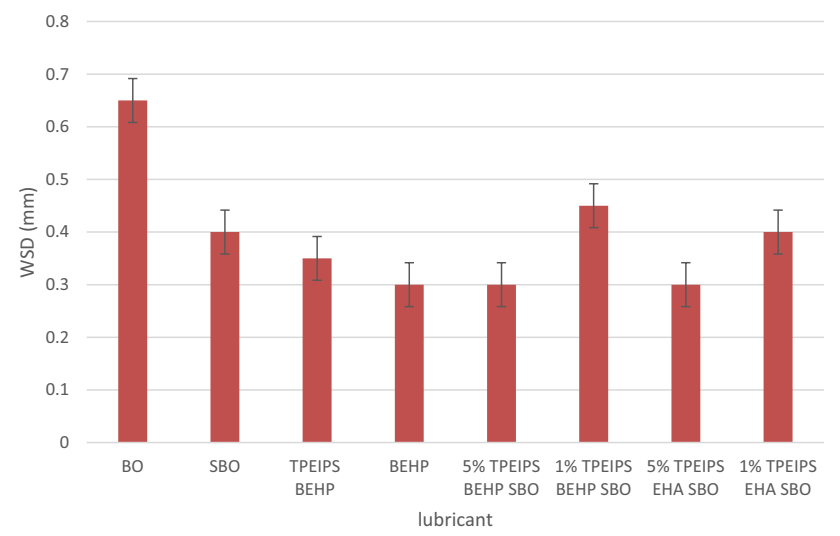

Fig. 5 Four ball testing of base oil (BO); sorbitan trioleate/base oil (SBO); neat TPEIPS EHA; neat TPEIPS BEHP; 1 wt\% TPEIPS BEHP SBO and $1 \mathrm{wt} \%$ TPEIPS BEHP SBO

additives did not deteriorate the performance, forming a resistive layer on the surface, which decreased the wear rate.

The IL/sorbitan trioleate blends were prepared at two different concentrations i.e. $1 \mathrm{wt} \%$ and $5 \mathrm{wt} \%$ in BO. It was observed that, as the concentration increases to $5 \mathrm{wt} \%$, both the anions show similar performance due to the uniform film formed on the surface evident from wear scar diameter (Fig. 5). The role of concentration is in the coverage on the surface and the ability to repair any protective film that is removed. With increased concentration a more uniform film forms on the surface and with time, if this protective film is removed then a higher concentration will result in faster repair and longer protection, both of which will result in less wear and damage.
The wear scar diameter of $5 \mathrm{wt} \%$ imidazoline-based ILs in the group III BO along with sorbitan trioleate as the emulsifier additive shows a decrease of $\approx 54 \%$, which was quite significant as compared to $\mathrm{BO}$ and the same as neat TPEIPS BEHP. Both the anions (BEHP and EHA) show the same WSD at $5 \mathrm{wt} \%$ concentration. To further understand which counterpart in the ILs plays a role in reducing the wear as comparison with the neat IL (TPEIPS BEHP) and the neat anion precursor (BEHP) was selected. When the BO with $5 \mathrm{wt} \%$ IL additives (TPEIPS BEHP and sorbitan trioleate) were compared with the neat precursor (BEHP) and the neat IL (TPEIPS BEHP), it was found that the $5 \mathrm{wt} \%$ ILs additives showed lower wear as compared to the TPEIPS BEHP neat and similar wear to the anion precursor neat BEHP. This suggest that the anion part of the ILs adsorbed on the steel surface forming a film through physisorption followed by chemisorption under the influence of friction and temperature. It was also evident from the wear and EDS test which shows presence of phosphorous on the surface showing the role of anion in determining wear response. While the neat BEHP performed well as the ILs synthesised, but in a practical oil formulation blends BEHP would never be used due to its acidity and long term stability. The increased basicity is the crucial parameter for lubrication which may results in better contending the stockpile acids produced from breakdown, contaminations, oxidation by-product which may cause threat of corrosion, sludge, varnish results in depletion of performance of lubricant and demand change in the oil.

The coefficient of friction were measured under reciprocating steel-steel contact at a force of $200 \mathrm{~N}$ for $1 \mathrm{~h}$ duration, with friction traces shown in Fig. 6 . The best performing concentrations from the 4-ball wear tests were selected for friction analysis. A drop in the friction

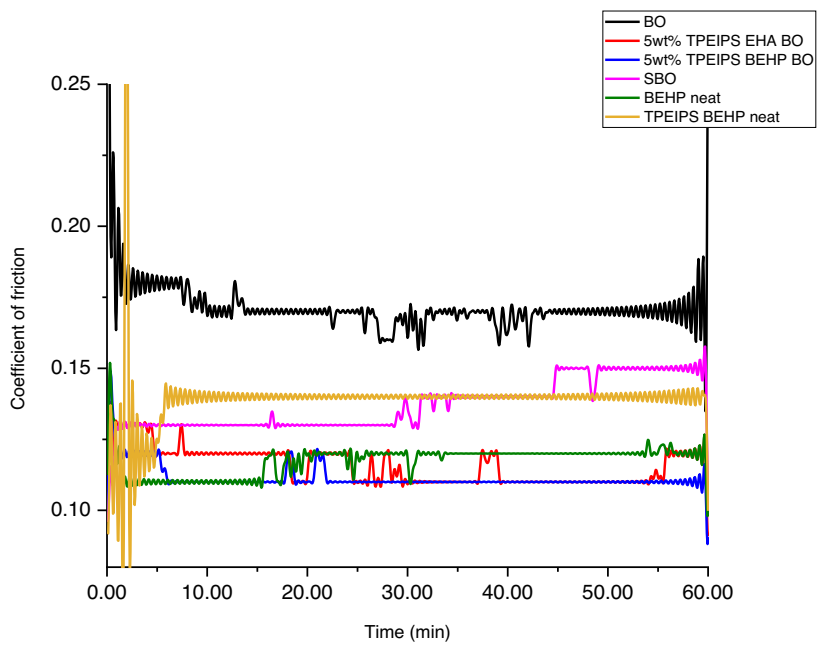

Fig. 6 SRV test of base oil (BO); sorbitan trioleate/base oil (SBO); neat TPEIPS EHA; neat TPEIPS BEHP; 1 wt $\%$ TPEIPS BEHP SBO and $1 \mathrm{wt} \%$ TPEIPS BEHP SBO 
of $39 \%$ can be seen when $5 \mathrm{wt} \%$ of the synthesized ILs was formulated in the III group BO. Similar to the wear, both the formulations at $5 \mathrm{wt} \%$ show comparable friction responses and the emulsifier also acts as frictional modifier, which was evident by the drop in friction of $\approx 28 \%$ when sorbitan trioleate was formulated in the BO. The sorbitan trioleate is known to form a protective layer or tribo-film preventing direct steel contact [33]. Also the role of cation and anion in frictional performance was assessed and it can be seen that the neat TPEIPS BEHP IL shows a higher coefficient of friction than when the IL is blended with emulsifier at $5 \mathrm{wt} \%$ in the BO, while the neat BEHP shows a similar performance to the blend.

These friction results are comparable and slightly better than ZDDP at $200 \mathrm{~N}$ [34]. We have also added MoDTC in the $\mathrm{BO}$ and found the coefficient of friction (COF) to approx. 0.160 in our study (see Supplementary information SI 6). Therefore as friction modifier it is performing better than well used additive MoDTC, which suggests these IL/emulsifier system is an environmentally viable alternative to conventional lubricants.

From both the wear and friction results, it was confirmed that at least for the TPEIPS BEHP IL, the anion part of the ILs plays a more significant role in improving the tribological performance. Furthermore, the tribology results show that both the ILs and emulsifier in the BO show promise as new as good antiwear and friction modifier additives.

\subsection{SEM}

SEM and EDS analysis of $1 \mathrm{wt} \%$ TPEIPS EHA/sorbitan trioleate/BO; $1 \mathrm{wt} \%$ TPEIPS BEHP/sorbitan trioleate/BO; sorbitan trioleate/BO; TPEIPS BEHP neat and anion precursor of BEHP was performed to understand the morphology of the wear scar, wear mechanism and the surface interaction between steel-steel contacts. The images for the IL/emulsifier/BO blends are shown in Figs. 7 and 8 while those for sorbitan trioleate/BO; TPEIPS BEHP neat and anion precursor of BEHP are given in supplementary information (SI).

From EDX analysis, if there is a film present on the surface then less of the metals underlying the film will be detected, so the amount detected will decrease. Thus, for the non-worn part of the sample for instance (See SI 4), $86 \mathrm{wt} \%$ of $\mathrm{Fe}$ is detected, while for the wear scar exposed to the blend containing TPEIPS EHA only $52 \mathrm{wt} \%$ is detected. There is also an increase in $\mathrm{O}$ from $1 \mathrm{wt} \%$ on the non-worn part to $9 \mathrm{wt} \%$ on the wear scar, as well as a significant increase in the amount of $\mathrm{C}$. These factors indicate that a relatively thick tribofilm has formed on the wear scar exposed to the blend containing TPEIPS EHA. For the blend containing TPEIPS BEHP the amount of Fe is similar to the non-worn surface at $82 \mathrm{wt} \%$, while $\mathrm{O}$ is elevated, which in conjunction with the presence of $\mathrm{P}$ suggests that a tribofilm has formed, but it is much thinner than that on the wear scar exposed to the blend containing TPEIPS EHA. The increase in Cr on the TPEIPS BEHP exposed wear scar from $1.5 \mathrm{wt} \%$ on the non-worn surface to $3 \mathrm{wt} \%$ is interesting and may indicate that for this additive $\mathrm{Cr}$ is more involved in tribofilm
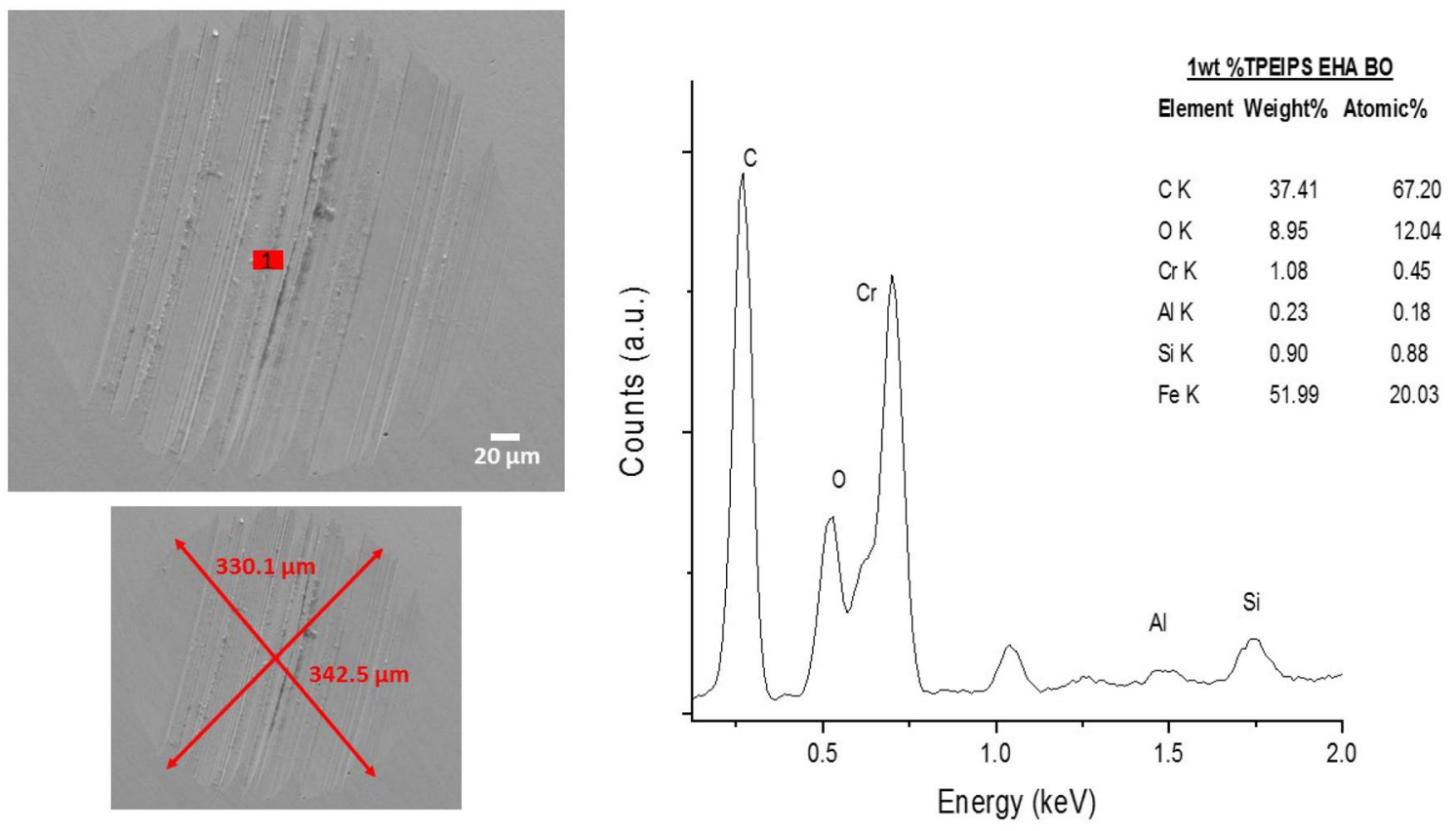

Fig. 7 EDS of 1 wt $\%$ TPEIPS EHA SBO 

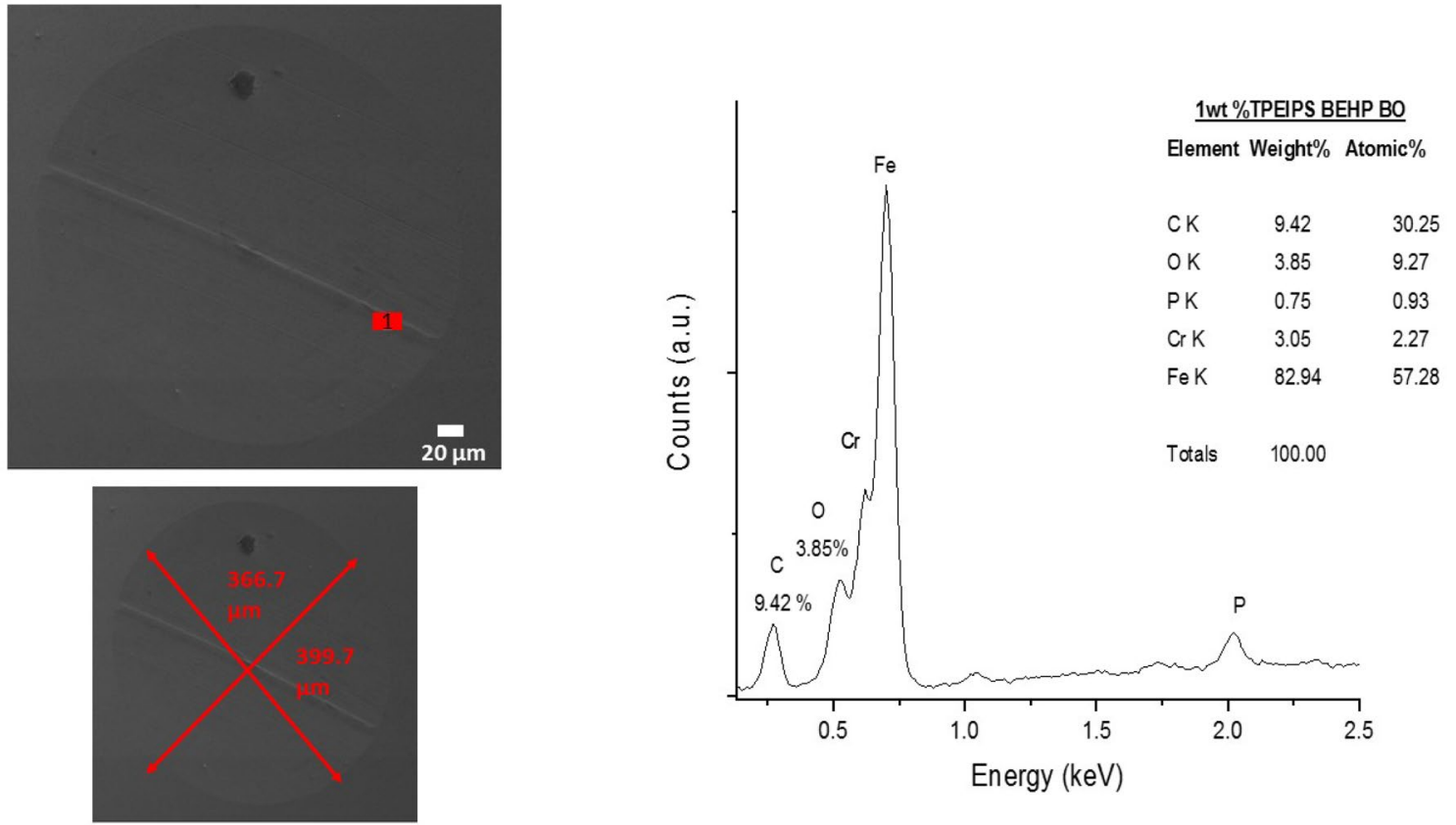

Fig. 8 EDS of $1 \mathrm{wt} \%$ TPEIPS BEHP SBO

formation. When only the surfactant is in the base oil (SBO) the wear scar had less reaction product on the surface, with only slightly less Fe than the non-worn surface and the lowest amount of $\mathrm{O}$ for all the wear scars, at $2.5 \mathrm{wt} \%$. The SBO blend did show an increase in $\mathrm{C}$, at $17 \mathrm{wt} \%$, suggesting that the main protective mechanism here is the adsorption of the long alkyl chain surfactant. More advanced surface analysis is required to better understand the tribofilm formation of these compounds.

In terms of how the IL containing blends are protecting the surface, when sorbitan trioleate was blended in the BO, it was found that the wear scar was similar to the $1 \mathrm{wt} \%$ TPEIPS EHA/sorbitan trioleate/BO (Fig. 7) but with BEHP anion (1 wt\% TPEIPS BEHP/sorbitan trioleate/BO, Fig. 8) the scar shows fewer scratches. It was observed that, there was phosphorous on the wear scar when the BEHP anion was included, which suggests the anion is involved in tribochemical film formation over the surface. Interestingly, for the neat TPEIPS BEHP, only Si was detected on the surface. This, along with the presence of $\mathrm{P}$ on the wear scar exposed to the oil containing TPEIPS BEHP confirms the presence of both cation and anion, but why only $\mathrm{Si}$ is observed when neat IL is used is not clear, however it is likely that micelle formation when the emulsifier is present changes how the $\mathrm{IL}$ is presented to the surface. This confirms that, in the BO, the anion of the IL adsorbs on the surface and tribochemical reactions occur which protect the surface of the steel. For the TPEIPS EHA containing oil, Si was detected on the wear scar and much elevated $\mathrm{C}$, even more than the sorbitan trioleate, since the anion is a carboxylate this suggests protection by the combination of the anion and cation as well as the sorbitan trioleate in reducing the wear (see SI, Fig. SI 1-3). The multiple protection mechanisms may explain why the TPEIPS EHA showed slightly lower wear at $1 \%$ than the TPEIPS BEHP.

\subsection{Seal Swelling Test}

Generally, natural or synthetic ester base stocks are more polar than mineral oils and may exert a seal shrinking and hardening effect on elastomers. Si is an element that has been linked to seal swelling [35] and so in order to observe the seal compatibility of one of the IL-based additives in BO, the ISO 6072-1986 (E) seal swell test was performed on viton elastomers. The mechanical and tribological performance of seals can be influenced by physico-chemical degradation of elastomeric materials. The change of mass and volume may increase the contact pressure in the interface seal, reducing the thickness of film lubricant, increasing temperature and generating more wear by abrasion and seal extrusion. The reduction in tensile strength and tear strength can result in a loss of mechanical resistance of a seal, which makes it susceptible to failure by rupture. The reduction in hardness of a seal decreases wear resistance and also roughness can modify the lubrication at the sealing interface altering the performance and seal life 
[36]. One of the ILs were selected, as silicon present in the cation of the IL could be oil incompatible [37], as a result one of the IL viz. TPEIPS EHA was selected. A thin segment of the viton rubber was immersed in the $5 \mathrm{wt} \%$ TPEIPS EHA BO formulation and allowed to remain in contact with the oil at $100{ }^{\circ} \mathrm{C}$ for 7 days. Upon completion of the test the viton pieces were tested for swell/shrinkage volume and hardness change compared to the initial volume and hardness values. The test was conducted in 2 sets, multiple reading in each sets and the average value was taken. There was only a $2.20 \% \pm 0.21$ volume change and $1.18 \% \pm 0.34$ change in the hardness of the viton rubber. This change in volume and hardness was insignificant, which shows elastomeric compatibility with the test lubricant and the optimum results should be little change in these parameter.

\subsection{Foaming Test}

The tendency of the lube to form foam is a serious problem which may lead to inadequate lubrication and loss of oil film causing mechanical failure. Foam testing was done using ASTM D892 which measures three sequences that differ only in measuring temperature.

Generally silicon-based structures are considered as known defoaming additives [22]. In both the synthesized ILs there was presence of silane-based functionality in the cation, therefore one of the $\mathrm{BO} / \mathrm{IL}$ blends was selected for this test in order to understand if the cation was able to impart multifunctionality to the formulations prepared. For this test one of the synthesized ILs viz. TPEIPS EHA was tested at $1 \mathrm{wt} \%$ concentration using the emulsifier additive, sorbitan trioleate. These were compared with the $\mathrm{BO}$, and the results was similar, with the foam formed was below the standard ISO 15380 limit $(150 / 0 ; 75 / 0 ; 150 / 0)$ of hydraulic oil. Thus, the composition does not show much foam as compared to most of the standards, but there was also no improvement in foaming ability when a BO containing a silane-based functional imidazoline IL was compared to the $\mathrm{BO}$ alone (Table 1).

Table 1 Foaming tendency of BO and 1\% TPEIPS EHA SBO

\begin{tabular}{lll}
\hline Lube & Parameters & Foam tendency \\
\hline BO & Sequence 1 at $24{ }^{\circ} \mathrm{C}$ & $60 /$ nil \\
& Sequence 2 at $93.5^{\circ} \mathrm{C}$ & $10 /$ nil \\
& Sequence 3 at $24{ }^{\circ} \mathrm{C}$ & $50 /$ nil \\
$1 \%$ TPEIPS EHA & Sequence 1 at $24{ }^{\circ} \mathrm{C}$ & $50 /$ nil \\
SBO & Sequence 2 at $93.5^{\circ} \mathrm{C}$ & $10 /$ nil \\
& Sequence 3 at $24{ }^{\circ} \mathrm{C}$ & $50 /$ nil
\end{tabular}

\section{Discussions and Mechanism}

Silane functionalised imidazoline ILs were synthesized and found to be oil miscible for a time of 1-2 days before phase separation. The lubricant additive sorbitan trioleate, which itself shows good lubricity, was added to improve the shelf life and oil stability of the formulations. The observed blends was miscible for more than seven months. The sorbitan trioleate/IL additives maintained the viscosity and thermal stability, while improving the friction and wear response as compared to the BO. The sorbitan trioleate was also acting in synergy with the IL, improving the overall tribological performance. For the TPEIPS BEHP IL, the role of the anion was crucial in determining the tribological performance, which was evident for COF, WSD and EDS data, comparing the oil blends, neat IL and anion precursor where the anion precursor reduced the wear more than the IL and there was the presence of phosphorus on the surface. The TPEIPS EHA did not show such an obvious effect of the anion, with both $\mathrm{Si}$ and elevated $\mathrm{C}$ on the wear scar suggesting the involvement of the anion, cation and sorbitan trioleate in the tribofilm formation.

With the increase in concentration from 1 to $5 \mathrm{wt} \%$ there may be the formation of a more uniform protective layer on the surface, demonstrated by a reduction of wear when the concentration was increased. As compared to the anion, the cation determines the miscibility [18, 38, 39], and it has been demonstrated that aliphatic cation structures viz. phosphonium and imidazoline-based ILs can be made oil miscible easily with low concentrations of surfactant additives, however dicationic and monocationic imidazolium ILs need high doses of surfactant and the stability of oil is shorter as compared to phosphonium and imidazoline-based ILs [14]. The role of the anion is crucial as elemental compositions such as phosphorous, boron and molybdenum showing well protected surfaces with low wear (evident from BEHP anion in this study) while in the case of carboxylate, the wear diameter observed was similar, but it has deeper scarring as seen in the SEM images. This also suggests that phosphorous-based anions are more capable of forming tribofilm by having chemical reactions on the steel surface and forming a resistive film on the surface while carboxylate anions form a lubricating film on the surface. To determine the multifunctionalities of these synthesized ILs, antifoaming and elastomeric compatibility testing was completed. It was found that these ILs shows less foam than the ISO 15380 standard maximum sequence of $150 / 0 ; 75 / 0 ; 150 / 0$ in hydraulic oils and also there was marginal volume and hardness change in the swelling test, which confirms the seal compatibility. 
Overall these IL may be oil miscible additives with good tribological and elastomeric compatibility.

Based on all the experimental results and analysis, the speculative mechanism of these novel TPEIPS EHA and TPEIPS BEHP IL can be summarized. The electrostatic action during the friction process causes, the electrons of the metal surface to escape, as a result the positively charged metal surface, adsorbs the negative charge of the IL anion. It adsorbs on the metal surface, forming a protective layer along with sorbitan trioleate. The active $\mathrm{P}$ element in TPEIPS BEHP can react with the steel surface, forming a compact tribo-film at the interface of the friction pairs, evident from EDS, in the case of TPEIPS EHA the anion, cation and possibly the emulsifier form a good shear boundary film that avoids direct metal contact under high pressure.

\section{Conclusion}

These novel ILs meet the aims of progressing towards environmentally friendly multi-functional additives that are free from halogen, with imidazoline proven to have anti-corrosive and anti-microbial properties [40]. These new ILs are free from sulfur and phosphorous (in the case of TPEIPS EHA), thus reducing environmental concerns. While the phosphorous was still present in the anion of TPEIPS BEHP IL, there is substantially less per molecule than in traditional additives. These additive types may become replacements for the conventional lubricant additives such as ZDDP and MoDTC as the frictional response was found to be comparable or better than these additives. These ILs were also found to be multifunctional, showing thermal stability, viscosity modification, elastomeric compatibility and antifoaming ability. The tribological performance also gives evidence that the anion clearly adsorbed on the metal surface and has more of a role in determining in friction and wear reduction, indicating that the anion can be further designed in such a way to promote superior tribological performance.

Supplementary Information The online version contains supplementary material available at https://doi.org/10.1007/s11249-022-01567-6.

Funding Open Access funding enabled and organized by CAUL and its Member Institutions. The author is thankful to the management of Indian Oil Corporation Ltd Research \& Development Centre and Deakin University for granting fellowship under Deakin-India Research Fellowship Programme.

Data Availability Enquiries about data availability should be directed to the authors.

\section{Declarations}

Conflict of interest The authors have not disclosed any competing interests.
Open Access This article is licensed under a Creative Commons Attribution 4.0 International License, which permits use, sharing, adaptation, distribution and reproduction in any medium or format, as long as you give appropriate credit to the original author(s) and the source, provide a link to the Creative Commons licence, and indicate if changes were made. The images or other third party material in this article are included in the article's Creative Commons licence, unless indicated otherwise in a credit line to the material. If material is not included in the article's Creative Commons licence and your intended use is not permitted by statutory regulation or exceeds the permitted use, you will need to obtain permission directly from the copyright holder. To view a copy of this licence, visit http://creativecommons.org/licenses/by/4.0/.

\section{References}

1. Holmberg, K., Andersson, P., Nylund, N.-O., Mäkelä, K., Erdemir, A.: Global energy consumption due to friction in trucks and buses. Tribol. Int. 78, 94-114 (2014)

2. Sharma, V., Erdemir, A., Aswath, P.B.: An analytical study of tribofilms generated by the interaction of ashless antiwear additives with ZDDP using XANES and nano-indentation. Tribol. Int. 82, 43-57 (2015)

3. Ekot, A.E., Ofunne, G.C., Bassey, C.E.: Using the physicochemical properties and the thermo-oxidation degradation products of ZDDP to justify its functions as an additive of choice for automotive crankcase oil formulation. Int. J. Eng. Sci. 3, 10-13 (2014)

4. Amiril, S.A.S., Rahim, E.A., Syahrullail, S.: A review on ionic liquids as sustainable lubricants in manufacturing and engineering: recent research, performance, and applications. J. Clean. Prod. 168(1), 1571-1589 (2017)

5. Arias-Pardilla, J., Espinosa, T., Bermúdez, M.D.: Ionic liquids in surface protection. In: Torriero, A.A.J. (ed.) Electrochemistry in Ionic Liquids: vol. 2: Applications, pp. 533-561. Springer, Cham (2015)

6. Bermúdez, M.-D., Jiménez, A.-E., Sanes, J., Carrión, F.-J.: Ionic liquids as advanced lubricant fluids. Molecules 14, 2888-2908 (2009)

7. Bridges, N.J., Rogers, R.D., Visser, A.E.: Ionic Liquids: Science and Applications. American Chemical Society, Division of Industrial and Engineering Chemistry, Washington (2013)

8. Cai, M., Yu, Q., Liu, W., Zhou, F.: Ionic liquid lubricants: when chemistry meets tribology. Chem. Soc. Rev. 49, 7753-7818 (2020)

9. Greaves, T.L., Drummond, C.J.: Protic ionic liquids: evolving structure-property relationships and expanding applications. Chem. Rev. 115, 11379-11448 (2015)

10. He, Y., Li, H., Qu, C., Cao, W., Ma, M.: Recent understanding of solid-liquid friction in ionic liquids. Green Chem. Eng. 2, 145157 (2021)

11. Nasirpour, N., Mohammadpourfard, M., Heris, S.Z.: Ionic liquids: promising compounds for sustainable chemical processes and applications. Chem. Eng. Res. Des. 160, 264-300 (2020)

12. Toledo Hijo, A.A., Maximo, G.J., Costa, M.C., Cunha, R.L., Pereira, J.F., Kurnia, K.A., et al.: Phase behavior and physical properties of new biobased ionic liquid crystals. J. Phys. Chem. B 121, 3177-3189 (2017)

13. Avilés, M.D., Carrión, F.J., Sanes, J., Bermúdez, M.D.: Bio-based ionic liquid crystal for stainless steel-sapphire high temperature ultralow friction. Wear 484-485, 204020 (2021)

14. Pandey, P., Somers, A.E., Hait, S.K., Forsyth, M., Ramakumar, S.S.V.: Short chain imidazolium ionic liquids: synthesis and oil miscibility in various base oil by use of surfactant as high performance friction and antiwear lubricant additive. Tribol. Lett. 69, $95(2021)$ 
15. Pandey, P., Somers, A.E., Hait, S.K., Forsyth, M., Ramakumar, S.S.V.: A novel approach to improve the oil miscibility and incorporate multifunctionality in ionic liquids as lubricant additives. Phys. Chem. Chem. Phys. 23, 3429-3440 (2021)

16. Pandey, P., Somers, A.E., Hait, S.K., Forsyth, M., Ramakumar, S.S.V.: Study of phosphonium based ionic liquid/dispersant additive interactions using spectroscopic technique for lubricant applications. J. Mol. Liq. 338, 116665 (2021)

17. Sakthivel, S., Velusamy, S., Gardas, R.L., Sangwai, J.S.: Experimental investigation on the effect of aliphatic ionic liquids on the solubility of heavy crude oil using UV-visible, Fourier transforminfrared, and 13C NMR spectroscopy. Energy Fuels 28, 6151$6162(2014)$

18. Yu, B., Bansal, D.G., Qu, J., Sun, X., Luo, H., Dai, S., et al.: Oilmiscible and non-corrosive phosphonium-based ionic liquids as candidate lubricant additives. Wear 289, 58-64 (2012)

19. Jiang, C., Li, W., Nian, J., Lou, W., Wang, X.: Tribological evaluation of environmentally friendly ionic liquids derived from renewable biomaterials. Friction 6, 208-218 (2018)

20. Hou, Q., Yang, X., Li, D., Cheng, J., Wang, S., Xiao, J., et al.: Tribological performance of hydrophobic and micro/nano triangle textured rake face of cutting tools. Appl. Surf. Sci. 571, 151250 (2022)

21. Plueddemann, E.P.: Nature of adhesion through silane coupling agents. In: Silane Coupling Agents, pp. 115-152. Springer, Boston (1991)

22. Jha, B., Christiano, S., Shah, D.: Silicone antifoam performance: correlation with spreading and surfactant monolayer packing. Langmuir 16, 9947-9954 (2000)

23. Salon, M.-C.B., Belgacem, M.N.: Competition between hydrolysis and condensation reactions of trialkoxysilanes, as a function of the amount of water and the nature of the organic group. Colloids Surf. A 366, 147-154 (2010)

24. Zhang, L., He, Y., Zhou, Y., Yang, R., Yang, Q., Qing, D., et al.: A novel imidazoline derivative as corrosion inhibitor for P110 carbon steel in hydrochloric acid environment. Petroleum 1, 237-243 (2015)

25. Mehedi, M.S.A., Tepe, J.J.: Recent advances in the synthesis of imidazolines (2009-2020). Adv. Synth. Catal. 362, 4189-4225 (2020)

26. Schauhoff, S., Kissel, C.: New corrosion inhibitors for high temperature applications. Mater. Corros. 51(3), 141-146 (2000)

27. Ditama, I., Muktiarti, N., Soegijono, B.: Imidazoline derivatives based on silane functional group as corrosion inhibitor on mild steel. In: AIP Conference Proceedings, p. 020019. AIP Publishing LLC, College Park (2020)

28. Zhou, F., Wang, H., Dai, Q.: Study on the Compound of Imidazoline Corrosion Inhibitor. IOP Conference Series: Earth and Environmental Science, p. 052001. IOP Publishing, Bristol (2018)
29. Turhan, Y., Turan, P., Doğan, M., Alkan, M., Namli, H., Demirbaş, Ö.: Characterization and adsorption properties of chemically modified sepiolite. Ind. Eng. Chem. Res. 47, 1883-1895 (2008)

30. Guo, W., Chen, S., Feng, Y., Yang, C.: Investigations of triphenyl phosphate and bis-(2-ethylhexyl) phosphate self-assembled films on iron surface using electrochemical methods, Fourier transform infrared spectroscopy, and molecular simulations. J. Phys. Chem. C 111, 3109-3115 (2007)

31. Kamal, R.S., Nassar, A., Ahmed, N.: Study the efficiency of some esters based on 2-ethyl hexanoic acid as synthetic lubricants. Egypt. J. Chem. 64, 2-3 (2021)

32. Koi, Z.K., Yahya, W.Z.N., Talip, R.A.A., Kurnia, K.A.: Prediction of the viscosity of imidazolium-based ionic liquids at different temperatures using the quantitative structure property relationship approach. New J. Chem. 43, 16207-16217 (2019)

33. Jason, Y.J.J., How, H.G., Teoh, Y.H., Chuah, H.G.: A study on the tribological performance of nanolubricants. Processes 8, 1372 (2020)

34. Peng, L., Li, J., Ren, T., Wu, H., Ma, C.: The tribological behaviour of a novel triazine derivative and its combination with ZDDP as additive in mineral oil. Ind. Lubr. Tribol. 63(3), 216-221 (2011)

35. Kekevi, B., Berber, H., Yıldırım, H.: Synthesis and characterization of silicone-based surfactants as anti-foaming agents. J. Surfactants Deterg. 15, 73-81 (2012)

36. Farfan-Cabrera, L.I., Gallardo-Hernández, E.A., Pérez-González, J.: Compatibility study of common sealing elastomers with a biolubricant (Jatropha oil). Tribol. Int. 116, 1-8 (2017)

37. Lewand, L.: Material compatiility of gasket materials in insulating liquids. In: 80th International Conference of Doble Clients (2013)

38. Han, D., Tang, B., Ri Lee, Y., Ho Row, K.: Application of ionic liquid in liquid phase microextraction technology. J. Sep. Sci. 35, 2949-2961 (2012)

39. Somers, A., Howlett, P., MacFarlane, D., Forsyth, M.: A review of ionic liquid lubricants. Lubricants 1, 3 (2013)

40. Mammadova, N., Mamedkhanova, S.: Synthesis and research into anticorrosion and bactericide properties of chlorinecontaining imidazoline complexes of distillated natural oil acids. Kimya Problemleri (2018). https://doi.org/10.32737/ 2221-8688-2018-3-343-350

Publisher's Note Springer Nature remains neutral with regard to jurisdictional claims in published maps and institutional affiliations. 